\title{
Study of Venous Thromobosis using Impedance Plethsmography
}

\author{
Miss Sarika Tapre ${ }^{1}$, Prof. Jyothi Warrier ${ }^{2}$

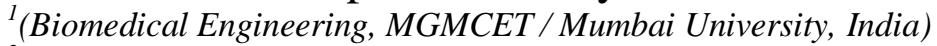 \\ ${ }^{2}$ (Biomedical Engineering, MGMCET / Mumbai University, India)
}

\begin{abstract}
This paper is on development of venous thrombosis using Impedance Plethsmography which can be used in institute laboratory, colleges for learning which is efficient to understand the actual working of Impedance Plethsmography. A small $1 \mathrm{~mA}, 50 \mathrm{KHz}$ current is injected into the body through two electrodes and the induced voltage is picked up using another pair of electrodes and placed inside the current electrodes. The amplitude of the signal thus obtained is directly proportional to the electrical impedance ( $\mathrm{Zo}$ ) offered by the body segment between the voltage electrodes. A change in the impedance, which is caused by physiological processes like blood clot, respiration, etc., modulates the amplitude of the carrier.

A battery operated low cost and compact Bioelectrical Impedance Meter is developed which can be used for estimation of body impedance, stroke volume, cardiac output, arterial pulse wave velocity and bone mineral density. It is used to measure body impedance from healthy subjects in a lab setup. These parameters may be used for estimation of body impedance.
\end{abstract}

Keywords: - BIA-Bioelectrical impedance analysis, DVT-Deep Venous Thrombosis, MRI-Magnetic resonance imagine, MVO-Maximum Venous Outflow, OIP-Occlusive Impedance Phlebography, VC-Venous Capacitance

\section{INTRODUCTION}

The Impedance Plethysmography, also called impedance test or blood flow, is a non-invasive test that uses electrical monitoring in the form of resistance (impedance) changes to measure blood flow in veins of the leg. Information from this test helps doctors to detect superficial vein thrombosis (blood clots).The Impedance Plethysmography is "Recording of instantaneous volume (of an object) by measurement of electrical impedance". It has, however become a synonym for "indirect assessment of blood volume changes in any part of the body from changes in the electrical impedance of the body segment" [1].

In this technique, a fixed $1 \mathrm{~mA}$ sinusoidal carrier at $50 \mathrm{KHz}$ is passed through the body with the help of two surface electrodes (called the current electrodes) and the voltage developed along the current path is sensed with the help of another pair of electrodes (called the voltage electrodes). The amplitude of the signal thus obtained is directly proportional to the electrical impedance (Zo) offered by the body segment between the voltage electrodes. A change in the impedance, which is caused by physiological processes like blood clot, respiration, etc., modulates the amplitude of the carrier. Electronic processing of this signal thus yields relevant physiological information [1]. There are various methods to detect venous blood clot, among which ultrasound is most commonly used. The patient size and shape limits the ability for ultrasound to provide a definitive answer. The second method is Venography, where in a radiologist injects contrast dye into small vein or foot and using fluoroscopy (video X-ray), watches the dye fill the vein in the extremity as it travel back to heart. The area of clot can thus be visualized. The third method known as computerized tomography (CT scan) is often the test of choice when suspicion of pulmonary embolus is high. Contrast material is injected intravenously, and the radiologist can determine whether a clot is present in pulmonary vessels. All these methods are invasive, costly and non-portable to measure the blood clot. Thus there is a need for a safe non-invasive technique that is rapid and convenient and provides reliable and sufficiently accurate estimates of human body composition outside the laboratory. Measurement of whole-body bioelectrical impedance is an approach that meets this need.

\section{BLOCKS OF SYSTEM CONFIGURATION}

The system uses the bio-impedance method. This developed hardware with 4 Electrode systems applies a small $1 \mathrm{~mA}, 50 \mathrm{KHz}$ ac current into body segment. This current induces the voltage across the voltage electrodes. From this voltage we calculate the impedance. The electrodes which are used in the project are made of copper mesh coated with tin to avoid damage due to environmental condition the copper is used for the better conductivity of the signal and to cut out the noise. These electrodes are suspended on human body. The 4 electrodes are placed at some distance, outer electrodes are current electrodes and inner electrodes are the voltage electrodes. These voltage and current signals are used to calculate the impedance. 


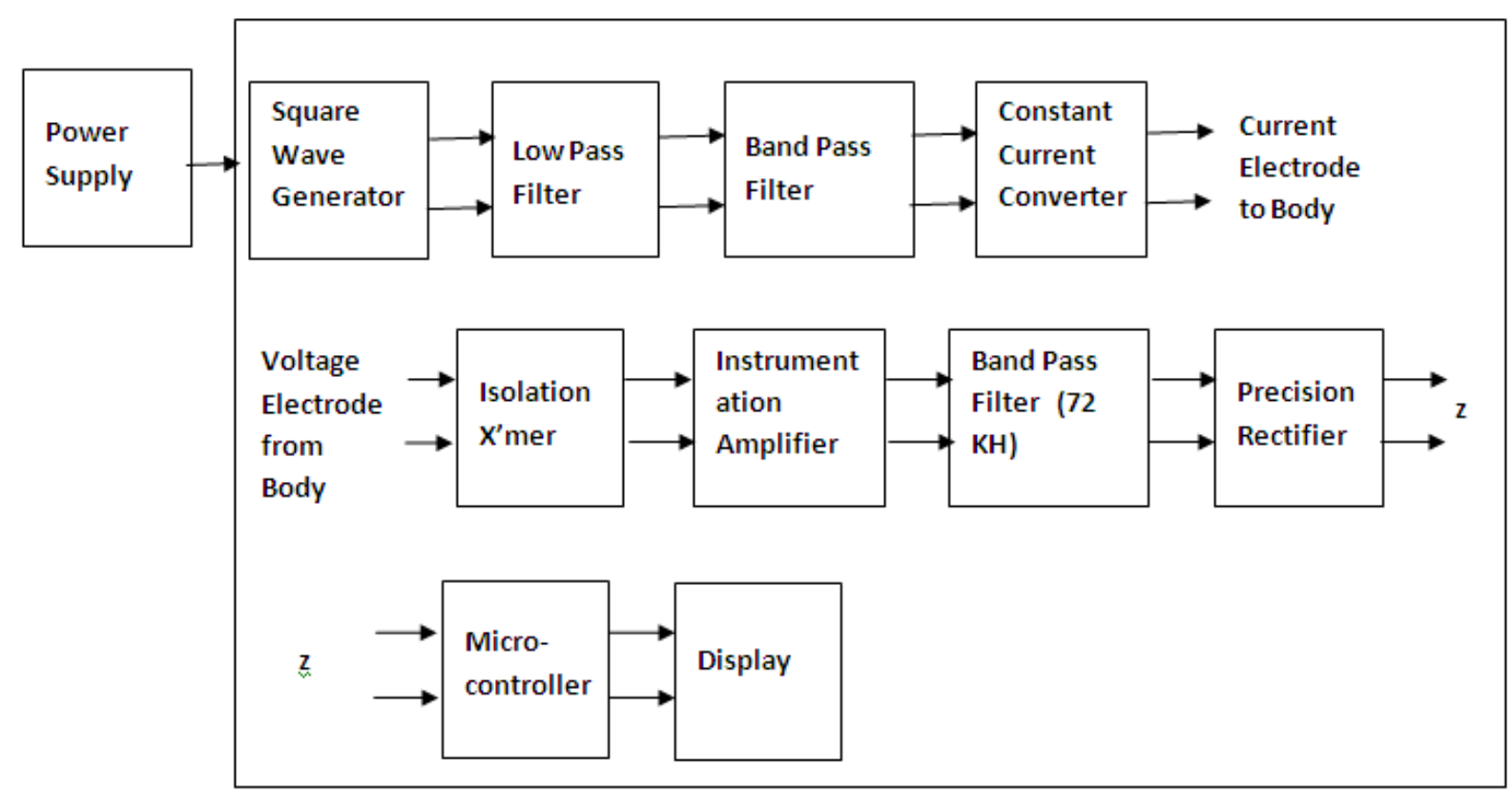

Fig 1.1 Developed system block diagram

The electrodes are the band type electrodes which are good conductor of electric current. These electrodes are made of copper mesh coated with tin to avoid damage due to environmental condition.

This is the main block architecture of the project. The system is a rechargeable DC battery operated and a low voltage drop out regulator IC which supplies $+5 \mathrm{~V}$ DC. As the whole designed system requires $\pm 5 \mathrm{~V}$ supply, the $+5 \mathrm{~V}$ output of the regulator is given to DC to DC converter which Converts the $+5 \mathrm{~V}$ supply to $\pm 5 \mathrm{~V}$ supply. The square wave generator type NE 555 is used for the generating the square signal of the $50 \mathrm{KHz}$. The square generator is a simple astable multi-vibrator operating at $+5 \mathrm{~V}$ supply which generates a square wave of 48 $\mathrm{KHz}$ which is required for the estimation of body impedance. Then the square signal passes through low pass filter.

The low pass filter is designed to convert the square wave in to sine wave with a cut of frequency of $240 \mathrm{KHz}$ to avoid interferences like radio frequency, electrical, etc. Op-Amp is used to design the low pass filter. After low pass filter band pass filter allows the frequency of $40 \mathrm{KHz}$ to $60 \mathrm{KHz}$ to noise interference. The band pass filter output which is in voltage form converted into the equivalent current designed in the specified frequency range. These circuits can be used as multi frequency constant current source independent of load [6].

The generated current of $1 \mathrm{~mA}, 50 \mathrm{KHz}$ is given to the body through current electrodes. The generated voltage in the body is sensed by isolation transformer. The isolation transformer isolates the body from electronics circuit. The output of isolation transformer is amplified by instrumentation amplifier. This amplified output is given to the full-wave rectifier.

The full wave rectifier output is DC voltage. This output of DC voltage is called impedance of body. This output impedance is connected to graphical LCD through microcontroller on which we can observe the change in impedance due to the blood flow.

\section{OCCLUSIVE IMPEDANCE PHLEBOGRAPHY (OIP)}

For the assessment of venous circulation, the proximal veins are occluded with the help of a tourniquet. The current electrodes are applied around abdomen (I1) and foot (I2).V1 and V2 are measured around the distal part of extremity $10-15 \mathrm{~cm}$ apart. The system is reset, OIP function is selected and then the tourniquet is inflated to 50 to $60 \mathrm{~mm}$ of $\mathrm{Hg}$. When $\Delta \mathrm{Z}(\mathrm{t})$ waveform reaches saturation, the cuff is deflated suddenly. Stop key is pressed after the waveform return to base level. The waveform is then printed.

Tourniquet $\mathrm{T}$ applied at thigh when inflated to $50 \mathrm{mmHg}$ stops venous returns from distal segment of the leg. This results in an increase in the amount of blood in the amount of blood in the body segment between the electrode V1 and V2 with every cardiac ejection and therefore a corresponding decrease in the impedance of the body segment. Linear segment of $\Delta \mathrm{Z}(\mathrm{t})$ curve showing a $\Delta \mathrm{Za}$ change in impedance during Ta second can be used for computation of arterial blood flow. Since veins have more capacity to accommodate blood than arteries due to their thin walls, this maximum change in impedance falling the occlusion of proximal veins was called Venous Capacitance (VC) as shown in fig. no. 1.2 Sudden deflection of tourniquet at this stage causes the vein to empty their blood rapidly. The rate of change of impedance ( $\Delta \mathrm{Zv} / \mathrm{Tv}$ in fig. 1.2) after the deflection of 
tourniquet is called Maximum Venous Outflow (MVO) as the veins are fully distended before the veins flow starts. VC and MVO thus obtained represents the status of venous circulation

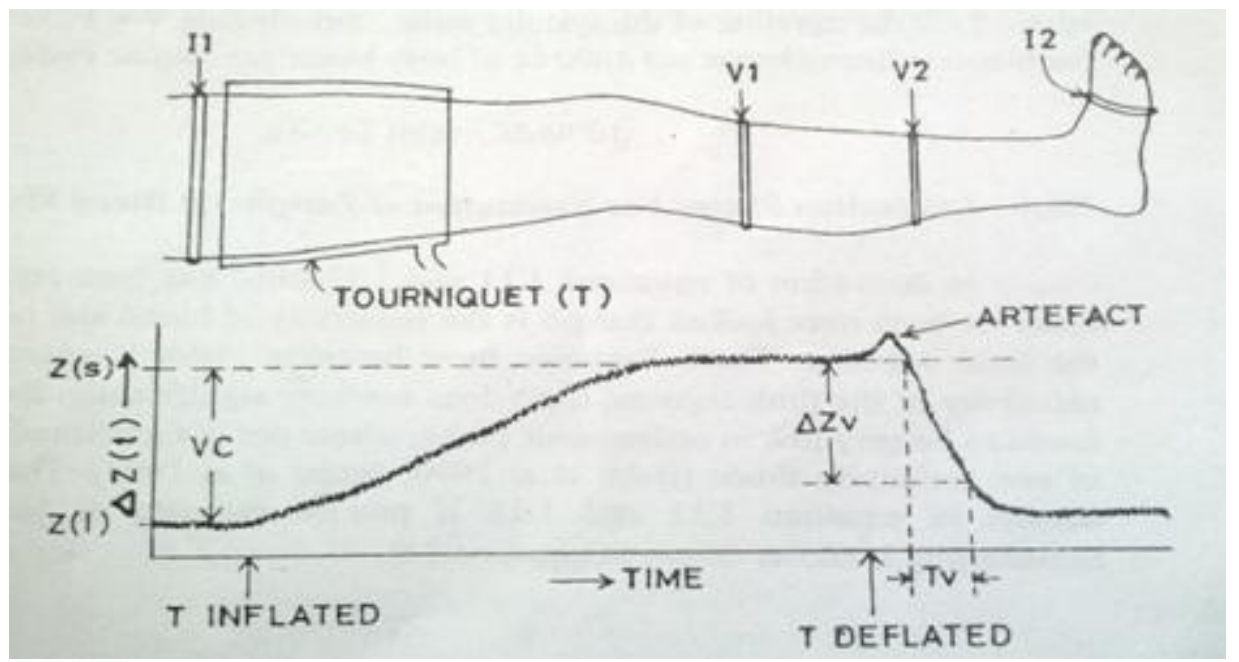

Fig. 1.2 Venous occlusion principle for the estimation of peripheral blood flow and assessment of venous circulation [1].

\section{RESULT}

The OIP record obtained from controller subject using the instrument developed is shown in figure no: 1.3 which is very similar that figure 1.2

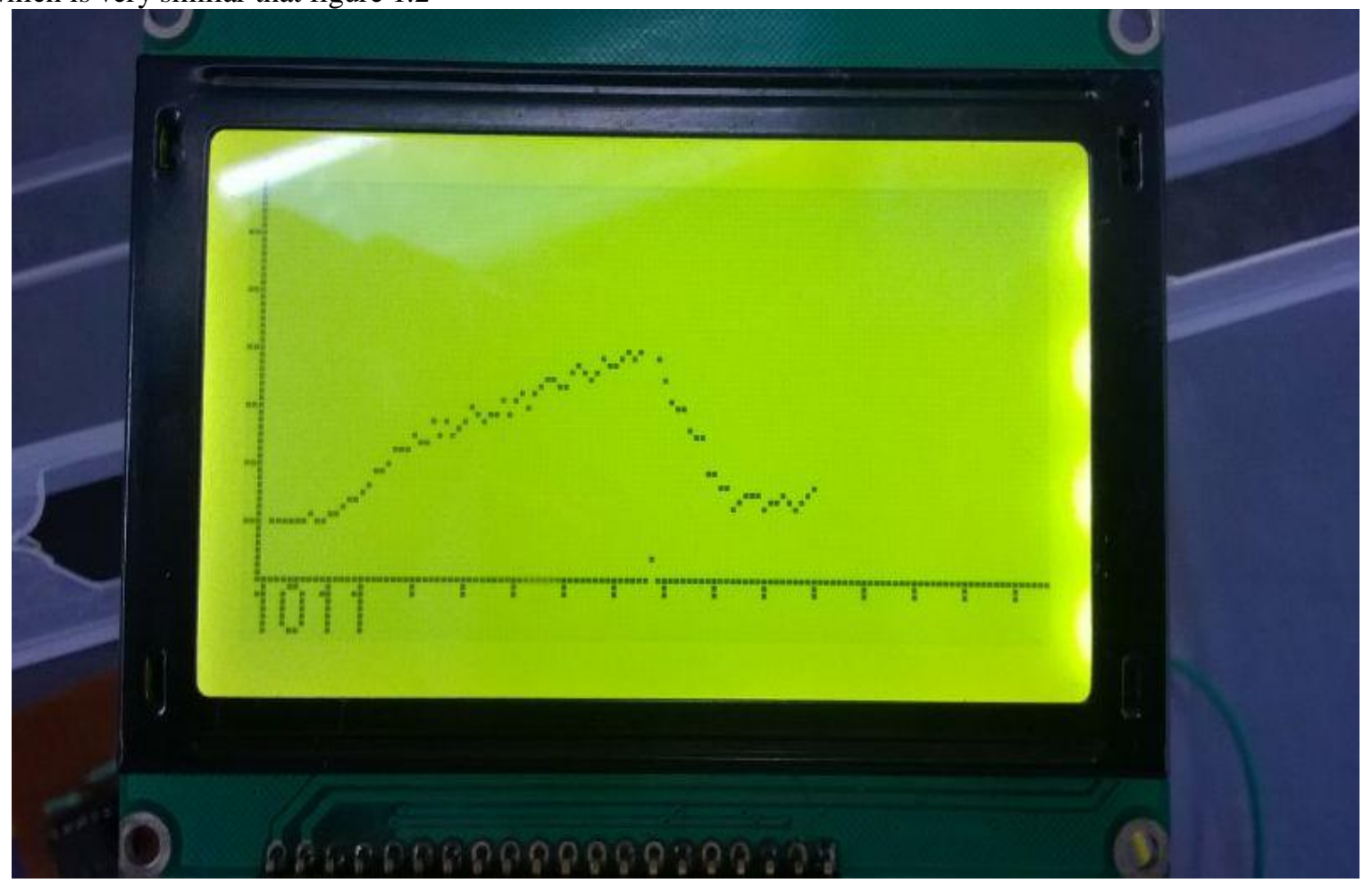

Fig. 1.3 Output Waveform.

\section{CONCLUSION}

Diagnosis of venous disorder and particularly of deep venous thrombosis is very important as the same can lead to fatal pulmonary embolisum. Keeping in view that all the patients who have undergone abdominal surgery are high risk patients of deep venous thrombosis, there is need for simple, safe and bedside non-invasive modality for screening such high risk patients.

Impedance Plethysmography method enables detection of Deep Thrombosis in all such high risk patients which is simple, safe and non-invasive. 


\section{ACKNOWLEDGEMENTS}

I would like to take this opportunity to thank MGM trust and Principal Dr. S. K. Narayankhedekar MGMCET for giving me an opportunity to carry out my second stage dissertation work.

I wish to acknowledge my extreme gratitude to my guide Prof. Jyothi Warrier for guiding me throughout the work. I have been greatly benefited by his valuable suggestion and ideas. I express my deep sense of gratitude towards Dr. G. D. Jindal for his valuable guidance and encouragement.

I also express my thanks to Prof. U. R. Bagal, Mr. Nazim momin, Mr. Suryapal, Mr. V.V. Gaikwad and my classmates for always giving a helping hand and encouragement during the work.

\section{REFERENCES}

[1] Electrical Impedance and Photo Plethysmography for Medical Applications", G. D. Jindal, T. S. Ananthakrishnan, S. K. Kataria, Vineet Sinha, Rajesh Kumar Jain, Sadhana A. Mandlik, A. R. Kini, Mousami A Naik, S. K. Singh, S. H. Sanghvi and G. Haridason Electronics Division BARC.

[2] Guyton, "Functional organization of human body and its internal environment," in Textbook of Medical Physiology, 11th ed. Philadelphia, USA: Elsevier saunders, 2006, ch. 1, sec. 1, pp. 3-9.

[3] Edwin Krales, "Bioelectrical Impedance Analysis and Body Composition," in [Body Positive Record as], [copyright 1999] @).

[4] Ursula G. Kyle, "Bioelectrical impedance analysis part 1: review of principles and methods," Clinical Nutrition, vol. 23, pp. 1226-1243, June, 2004.

[5] Paul Deurenberg, "Changes in fat free mass during weight loss determined by bio impedance analysis and by densitometry," The American journal of Clinical Nutrition, vol. 49, pp. 33-36, Mar, 2014.

[6] Baker L. E, "Principles of the impedance technique", IEEE Engineering in Medicine and Biology Magazine, vol. 8, no. 1, pp. 11-15.

[7] Barnett A. and Bagno S, "The physiological mechanisms involved in the clinical measure of phase angle", American Journal of Physiology, vol. 114, pp. 366-382.

[8] Schwan H. P. and Kay C. F, "The conductivity of living tissues", Annals of the New York Academy of Sciences, vol. 65, no. 6, pp. 1007-1013.

[9] Baumgartner R. N et. al, "Bioelectric impedance phase angle and body composition", The American Journal of Clinical Nutrition, vol. 48, pp. 16-23.

[10] Lukaski, H. C. and Bolonchuk W. W, "Theory and validation of the tetrapolar bioelectrical impedance method to assess human body composition", pp. 49-60 in "In Vivo Body Composition Studies", edited by Ellis K.J., Yasumura S. and Morgan W.D., eds. London: The Institute of Physical Sciences in Medicine.

[11] Subramanyan R., Manchanda S. C., Nyboer J. and Bhatia M. L, "Total body water in congestive heart failure. A pre and post treatment study", Journal of the Association of Physicians of India, vol. 28, no. 9, pp. 257-262.

[12] Barnett A, "The basic factors in proposed electrical methods for measuring thyroid function, III. The phase angle and the impedance of the skin", Western Journal of Surgery, Obstetrics, and Gynecology, vol. 45 , pp. $540-554$.

[13] Lukaski H. C, "Methods for the assessment of human body composition: traditional and new", The American Journal of Clinical Nutrition, vol. 46, pp. 537-556.

[14] Spence J. A., Baliga R., Nyboer J., Seftick J. and Fleischmann L, "Changes during hemodialysis in total body water, cardiac output and chest fluid as detected by bioelectric impedance analysis", Transactions American Society for Artificial Internal Organs, vol. 25, pp. 51-55.

[15] Hoffer E. C., Meador C. K. and Simpson D. C, "Correlation of whole-body impedance with total body water volume", Journal of Applied Physiology, vol. 27, pp. 531-534.

[16] Nyboer J, "Electrical Impedance Plethysmography", Charles C Thomas, Springfield, IL.

[17] Thomasset A, "Bio-electrical properties of tissue impedance measurements in clinical medicine", Lyon Medical, vol. 207, pp. 107-118.

[18] Bolot J-F., Fourier G., Bertoye A., Lenior J., Jenin P. and Thomasset A, "Determination of the lean body mass in adult using the impedance method", Nour. Presse Medical, vol. 6, no. 25, pp. 2249-2251.

[19] Ducrot H., et. al., "Determination of extracellular fluid volume in man by measurement of whole body impedance", Presse Medical, vol. 51, pp. 2269-2272.

[20] B R. Patil, "Bioelectrical Impedance Analysis for Bone Density Measurement," Ph.D. dissertation, Electrical Engineering, Mumbai University, Mumbai, Maharashtra, 2008.

[21] Paul B Pencharz and Maria Azcue, "Use of Bioelectrical impedance analysis in clinical management of malnutrition", American Journal of Clinical Nutrition, pp. 485-488.

[22] Ursula G. Kyle, et. al., "Bioelectrical impedance analysisFpart I: review of principles and methods", Clinical Nutrition, vol. 23, pp. 1226-1243. 